around was quite pale; they were each two centimetres in chief diameter and so well encapsulated that their mere weight almost brought about their enucleation. I have seen the same thing in a second case.

Ranke remarks ${ }^{3}$ that it would be of interest to determine whether the cushion is present or not in the anthropoid apes. As examples of such $\mathbf{I}$ have been able to examine from the College stores the heads of two infant chimpanzees (Anthropopitheous troglodytes). One of these, a female, had no teeth erupted; the umbilical cord was separated and the cicatrix formed. From the vertex to the tip of the coccyx the measurement was ten inches. In the horizontal section carried through the cheek between the jaws no sucking cushion was displayed, nor was any fat discernible to the eye in the subcutaneous tissue of the cheek; nor was there any in that of the buttock or front of the thigh. Nevertheless, a microscopic section of the parts revealed the presence of a group of fat cells in the position of the cushion and evidently its representative. In the second specimen the central incisors, both upper and lower, were just appearing through the gum. In the proper anatomical position there is a circumscribed sucking cushion seven millimetres in diameter. There is a thin layer of subcutaneous fat on its outer side which extends for a short distance forwards in the cheek.

Passing lower down the scale. In a stillborn Sacred Baboon in which the umbilical cord was still attached, and the foetus at term, I found on making the usual horizontal section that the sucking cushion was well differentiated though not large. There was very little subcutaneous fat over the buccinator; the cushion is sharply encapsulated, spherical, not more than six millimetres in diameter, and lies immediately in front of the anterior border of the masseter muscle. Notwithstanding its presence there is in both the chimpanzee and the baboon a complete absence of the rotundity of the cheek which is so pronounced in the human fœetus at birth, and which is indeed a peculiarly human feature. The absence of this rotundity in the chimpanzee and baboon is due partly to the small amount of fat there is in the subcutaneous tissue of the cheek in general, and partly to the stretch or length of cheek itself arising from the extreme prognathism of the simian face, the sucking cushions lying at the most posterior part of the cheek, and being, moreover, of relatively small size as compared with those in the human infant.

Why the fat of the sucking cushion should withstand absorption during the emaciation of the rest of the body has not been satisfactorily explained. One may suppose that the mechanical function of bearing a higher degree of intermittent pressure than the surrounding fat leads to an increased vascularity, and associated with this one has to remember the isolation of the mass and the narrowness of its attachment. Absorption would less readily occur through the vessels of such a pedicle than in the case of the general subcutaneous fat, the vascular connexions of which with the surrounding parts are more intimate.

Mr. A. Mavrogordato was good enough to make a comparative examination of the fat of the cushion and the adjoining fat of the cheek. The fat was saponified, the fatty acids liberated by means of sulphuric acid, \&c., and the iodine value of the purified acids estimated; their iodine value was the same.

$$
3 \text { Ranke : Loc. cit. }
$$

Royal College of Physicians of London.An extraordinary Comitia was held on March 19th. In the absence of the President Dr. Norman Moore occupied
the chair. A report, dated March 5th, was received from the delegates of the two Colleges appointed to consider a scheme of conjoint examinations under Statute 123 of the University of London. The report was as follows: "The delegates beg to recommend that they be authorised by the Royal Colleges to confer with representatives of the medical schools in London and other bodies on the University question." On the motion of Sir W. H. Allchin, seconded by the registrar (Dr. E. Liveing), the report was adopted. The rest of the business on the agenda was declared to be seoreta Collegii. The chairman then dissolved the Comitia.

\section{ON SOME ABNORMALITIES OF OCULAR MOVEMENTS,}

WITH PARTICULAR REEERENCE TO "ERRONEOUS PROJECTION" IN CASES OF PARALYSIS OF MUSCLES OF THE EYE-BALL, ESPECIALLY IN CASES OF

PARALYSIS OF AN EXTERNAI RECTUS-OUT-GOING (CENTRO-PERIPHERAL) $v$. IN-GOING (PERIPHERO-CENTRAL)

\author{
CURRENTS.
}

BY J. HUGHLINGS JAGKSON, M.D. ST. AND., F.R.C.P. LOND., F.R.S.,

CONSULTING PHYSICIAN TO THE LONDON HOSPITAL AND TO THE NATIONAL HOSPITAL FOR THE PARALYSED AND EPILEPTIO;

$$
\text { AND }
$$

LESLIE PATON, M.B. CANTAB., F.R.C.S. ENG., ASSISTANT OPHTHALMIC SURGEON TO ST. MARY'S HOSPITAI, PADDINGTON, W., AND TO THE NATIONAL HOSPITAL FOR THE PARALYSED AND EPILEPTIC.
FOT

PART I.-Preliminaries.

IN a case of paralysis of an external rectus, suppose that of the right eye, there is, when the patient looks at an object on his right, "erroneous projection" of that object, seeming displacement of it to the right. This symptom has been attributed, in accordance with a theory (we shall call it the "out-going theory") held by Bain and Wundt, to a greater degree than ordinary of the "out-going, a centroperipheral, current," a current from cerebral motor centres. The following, a translation by one of us (L. P.) from Helmholtz's "Handbuch der Physiologischen Optik," second edition, 1896, is a statement of "the out-going theory." (No italics in original) :-

"We ascribe then the direction of our line of vision either to the actual placing of the globe itself or to the correlated lengthening or shortening of the eye muscles. That we do not also ascribe the direction of the line of vision to the tension of the eye muscle is because, in those cases in which paralyses of single eye muscles suddenly take place the patients, if they try to move their eye in that direction in which movements no longer can take place, see false movements which produce double pictures when the other eye is opened. If, for example, the external rectus of the right eye or its nerve is paralysed, that eye can no longer be moved over to the right side. So long as the patient turns it only to the inner side it makes normal movements and he has a true sense of the direction of objects in his field of vision. As soon as he seeks to turn it outwards to the right it no longer obeys his will, but remains stationary in the middle line, and objects are seemingly displaced to the right although the position of the eye and of the retinal picture in the eye remains unaltered. In such a case of a paralysed muscle there follows as a result of the act of volition neither movement of the eye nor contraction of the muscle which should contract, nor even an increased tension in this muscle. The volitional impulse has no result at all outside the nerrous system, and yet we judge the direction of the line of vision as if the act of willing had produced its normal consequences; we believe that the visual axis in the example taken has been displaced to the right and since the position of the retinal image on the retina of the paralysed eye remains unaltered, it appears to us as if the objects had made this erroneously assumed movement of the globe.

"If the paralysis is not complete so that the eye can still fix an object lying a little to the outside, but requires for that purpose a greater amount of nerve stimulus to the paretic muscle than is usual, there again arises a false conception of the direction of the visual axis, and of the position of the object, as one can learn if we ask the patient
grasp quickly at the object. He grasps at first beyond the object.

"These phenomena place it beyond doubt that we judge the direction of the visual axis only by the volitional act by means of which we seek to alter the position of the eyes."

There is another theory, one very different from that stated in the quotation just given. This second theory, we may call it the "in-going theory," that of periphero-central currents, is the one which in these days is most widely accepted. Indeed, in regard to the first theory, "the outgoing theory," Titchener in his "An Outline of Psychology," p. 247, says "there is no such thing as a motor-cell sensation, a sensation corresponding to the innervation of a muscle or group of muscles.'

In this article we consider the rival theories "in-going $v$. out-going" only in regard to ocular movements and to certain symptoms of paralysis of some of the muscles of the eyeball. It may be well to add that the concern which any muscles, and any sensory or motor centres in relation with the double innervation of muscles, have, or may have, either in the estimation of weight or of degrees of resistance is not considered in this article. One of us (J. H. J.) has long held the doctrine that the "out-going" current, a motor cerebral current, is concerned in the physical processes during the exteriorisation and the placings of images (percepts standing 
for what we call external objects) and with the physical processes during referrings of "sensations" to parts of the body.

Before going further, something must be said about the two expressions, "muscles" and "movements of muscles," with limitation of remark to the ocular musculature. The expression "movements of muscles" has a clumsy sound, but it is difficult to avoid using some such expression. It must be well kept in mind that muscles are not represented in their individual character by motor centres but as they are combined into movements; the same muscles are represented in different centres in different combinations, that is in movements of different kinds; using a poor analogy, as different tunes are playable on the same keys of a piano.

More particularly, and for the present speaking with disregard of centres of the Cerebellar Sub-system, there are different orders of representation of movements of ocular muscles in centres of all levels of the Cerebral Sub-system (it must, however, be said that the lowest level belongs to both sub-systems; it is cerebro-cerebellar). It is suggested (J. H. J.) that there is a first representation of ocular muscles in simple movements, a "nuclear representation" of them, in the lowest level ${ }^{1}$ (by certain centres (nuclei) of the "true spinal system" of Marshall Hall). Presumably these nuclei, some lowest level (cerebro-cerebellar) motor centres are those morbidly affected in cases of ophthalmoplegia externa. No doubt they were the centres damaged in the case of George D., detailed in Part V., and possibly there was a similar location of lesion in a case Mr. Priestley Smith refers to which will be mentioned again later. A further suggestion is that there is a second, an indirect, representation (a rerepresentation) of ocular muscles in more complex movements by centres of the middle level ("motor region" of the cortex cerebri). The ocular paralysis or, better, the movement of the eyes lost, which permits lateral deviation of the eyes from the side of the body paralysed in cases of ordinary cerebral hemiplegia, is due either to disease of, or of part of, the middle level or to a lesion (of the internal capsule) which cuts the middle level off from lower, lowest level, centres. Still another suggestion is that there is a third, a doubly indirect, a still more complex, representation (a re-re-representation) of movements of the ocular muscles in the highest level (præfrontal lobe); from the third level, the highest level (the "mental centres"), motor impulses depart and reach the oculo-motor periphery by intermediation of the middle and lowest levels.

Movements of both eyes in conjunction are represented in each half of the brain. Those which are most specially represented, or represented in greatest number, in cerebral centres are lateral movements, movements of both eyes during looking to right or to left; but other kinds of movements of ocular muscles are represented in each half of the brain. As one of us (J. H. J.) has remarked in THE LANCET of April 28th, 1894, “...... every movement called voluntary will be represented in the cerebral hemispheres, and thus there must be representation in them of all ocular movements a man can effect when he tries. I asked Dr. Risien Russell to make researches on this matter. At my suggestion he cut the right external rectus and the left internal rectus of a monkey, thus rendering movements of the two eyes to the right impossible. Upon faradic excitation of the animal's left cortical eye area the eyes turned directly upwards or directly downwards according to the particular part of the eye area stimulated." Dr. Risien Russell has published an account of his researches (on the cortical representation of movements of ocular muscles) in two valuable papers in the Journai of Physiology, Vol. XVII., Nos. 1 and 5, 1894.

In some cases of the common form of cerebral hemiplegia there is, as was first pointed out by Vulpian and Prevost, conjugate deviation of both eyes from the side paralysed the implied cerebral motor nervous arrangements in healthy people, those destroyed in cerebral hemiplegia, with the morement they represent, have been likened by M. Foville to the arrangement of reins, each with two slips, for driving a pair of horses. There is in many of the cases of hemiplegia mentioned, turning of the head to the side to which the eyes turn, but here we deal only with turning of the eyes. In left hemiplegia the turning of the eyes is to the right and this is due to a particular paralytic condition, that is to say, to loss of cerebral motor nervous arrangements

1 Only the motor divisions of levels are dealt with in the text. for the movement of turning both eyes to the left. In a convulsion, one due to cortical disease, of, or beginning in a part of, the left side of the body, and of extensive range, the turning of the eyes is to the left and is owing to an overdevelopment of that movement of the eyes which is lost in cases of left cerebral hemiplegia; when such a convulsion is over the eyes may be temporarily turned to the right ${ }^{2}$; this post-paroxysmal turning is an indirect consequence of exhaustion by the intense, an epileptic, discharge of those nervous arrangements which in the paroxysm produces turning of the eyes to the left. ${ }^{3}$

Mr. Priestley Smith has considered abnormalities of ocular movements and paralyses of ocular muscles in several valuable papers. The following remarks by ${ }_{4}$ him bear closely on the dictum that ocular muscles are represented by motor centres in different combinations, that is as different movements. In Heath's Dictionary of Practical Surgery, vol. ii.," p. 87, in an' article entitled "Affections of the Ocular Muscles," Mr. Smith, in regard to conjugate lateral deviation of both eyes in cases of hemiplegia, wrote: "Although the two recti which are concerned in this paralysis are totally inactive for conjugate movements, they may remain active for convergent and divergent movements; thus in a case observed by the writer (Roy. Lond. Ophth. Hosp. Reports, Vol. VIII., p. 185) neither eye could to the smallest extent follow the movement of an object moved laterally before the patient's face, but both eyes performed movements of convergence when the object was moved from a farther to a nearer point, in line with the oblique direction of the eyes."

Wherever, in whatever level, the lesion may have been in the case Mr. Priestley Smith investigated, its symptomatology showed that as a consequence of disease, ocular. muscles may not serve for the execution of certain movements and may yet serve in the execution of movements of other kinds.

Although in this article we deal with cerebral representations, and sometimes with lowest level representations, of movements of ocular muscles, cerebellar representations of movements of those muscles are of great importance in neurology, especially in medical neurology; the researches of Ferrier in this regard are well known. A reference to important researches by Dr. R. H. Clarke and Sir Victor Horsley on cerebellar movements of ocular muscles, will be found in Brain, Part 116 (1906), pp. 463 et seq. Sir Victor's observations on what he calls "the temporocerebellar complex" raise the question of orientation or, to use his words, "the locomotory appreciation of distance and position in space," to a higher plane by showing certain relations between a part of the cerebrum, the temporal lobe, and parts of the cerebellum and the bearing of these relations on a higher and wider research.

When speaking of the process of development of movements of muscles, the masterly researches of Sherrington on

2 See a very important contribution to neurology by the late Dr. Charles Beevor, Brain, vol. v., pp. 56 and seq., in which he dealt with "Post-epileptic Conjugate Deviation of the Eyes."

3 In an old paper, Brit. Med. Jour., June 2nd, 1877, one of us (J. H. J.) has written, in perhaps too ridiculous a jumble of terms, as follows, deviation [in hemiplegia] is analogous to dropping one rein (the righ one, we will suppose) then the heads of the horses (supposing the lef rein to be, so to speak, in tone) turn to the left. Here the secondary rein to be, so to speak, in tone) turn to the left. Here the secondary a clumsy mixture of illustrative terms, we may say that when the a clumsy mixture of illustrative terms, we may say that when the reach the head of the horse on the right, as the slip of rein to that side reach the head of the horse on the right, as the slip of rein to that side is paralysed; but in the effort to make it move, a strong current passes
by the other slip to the head of the horse on the left-that horse's head by the other slip to the head of the horse on the left-that horse's head undergoes strong 'secondary' deviation. The lateral deviation shows that after the nerve-fibres of the ocular nerve-trunks have entered the central system (if we may, for convenience, trace them backwards way) they are-partly probably by the intermediation of several centresredistributed. It shows that far abore their points of entrance, or rather exit, the nerve-fibres of the ocular muscles are rearranged in each cerebral hemisphere in complex ways for particular movements of both eyeballs. There is no such thing as paralysis of the muscles applied by the third nerve, or sixth nerve, from disease above the crus cerebri. It must be kept well in mind that the cases of hemiplegia dealt with in the text are cases of cerebral, hemiplegia. In a man with right hemi-
plegia from disease of the pons varolii (a case which one of us [J. H. J.] plegia from disease of the pons varolii (a case which one of us [J. H. J.]
recorded, Medical Times and Gazette, Jan. 3rd, 1874) both eyes were recorded, Medical Times and Gazette, Jan. 3rd, 1874) both eyes were the text are those from cortical discharges. One of us (J. H.J.) has the text are those from cortical discharges. One of us (J. H.J.) has 1887 , p. 276 , the case of a woman in whom there were convulsions, to 1887, p. 276, the case of a woman in whom there were convulsions, to some extent the occasional "mobile opposites" of the permanent paralysis in the case of the man mention above, the case of hemplegia from disease of the pons varoli ; in her there were paroxysm turning of both eyes to the left. 
Reciprocal Innervation have to be considered. The following quotation is from his book, "The Integrative Action of the Nervous System," p. 280. "If III. and IV. cranial nerves of one side, e.g., left, have been severed, so that rectus externus remains the only unparalysed ocular muscle, appropriate excitation of the cortex cerebri produces conjugate movement of both eyes towards the opposite side-i.e., from left toward right, the left eye travelling, however, only so far as the median line (not italics in original). Inhibition of the tonus and of the active contraction of rectus externus can thus be elicited from the cortex." Borrowing from what C. S. Myers writes (p. 225 of his "A Text-book of Experimental Psychology"), we add to the foregoing " normally the contraction of one group of ocular muscles is accompanied by active relazation or inhibition of the opposing group of muscles." 4 Sherrington's researches deserve very careful consideration from medical neurologists. It has been said that upholders of what the writers of this article call "the out-going explanation" of erroneous projection in a case of paralysis of a right external rectus, neglect the effects due to the relaxation of the internal rectus of the right eye.

It will be convenient, for simplification of exposition, to speak in many parts of this article of ocular muscles when we are dealing with what are really ocular movements or, as we might say, when we are speaking of inabilities of lowest level oculo-motor or of higher level oculo-motor centres, to make, or to make completely, some particular ocular movement. Yet it is to be kept in mind that in most of the cases of paralysis we deal with, say paralysis of an external rectus, the whole of the nervous system is supposed to be healthy with the exception of disease of a small nerve trunk, the right sixth cranial nerve. Nevertheless the whole nervous system, or rather certain elements of every level and interconnexions of levels by nerve fibres (the sixth cranial nerve excepted) is engaged when the patient, whose right external rectus is paralysed, looks to the right when told to do so, and who whilst doing so has the three symptoms, diplopia, secondary deviation and erroneous projection; certain parts of the central nervous system are only abnormally engaged in the sense of being super-normally, hyper-physiologically, engaged, they are not affected by any pathological process. This case is the best which can be given to show what is meant by the term "Physiological Factor" in symptomatologies of nervous maladies.

When considering movements of muscles, something should be said of muscle-spindles. It has been stated that ocular muscles have no spindles. But recently Dr. Farquhar Buzzard ${ }^{5}$. has discovered spindles in these muscles. He divides his observations into two parts, "(1) The very occasional presence of easily recognised muscle-spindles in ocular muscles, and (2) the possibility that there are modified forms of spindles in ocular muscles as a general rule."

We now come to a more direct consideration of the "ingoing theory."

Recapitulating, we take for illustration the case of a man whose right external rectus is paralysed from disease of the sixth cranial nerve trunk supplying that muscle. When this patient tries to look to his right-motor cerebral discharge of nervous arrangements for moving both eyes in parallelism to the right-his right eye does not go out, the way being blocked by a destruction lesion of some part of the conrse of the nerve trunk to the external rectus, but the patient's left eye goes in too much, from too great contraction of the left internal rectus, a muscle supplied by a twig from the intact left third nerve: this over-contraction is the symptom which ophthalmic surgeons call "secondary deviation." The left eye may be covered during the investigation, but since convergence $^{6}$ of even a closed eye helps to determine the sense of direction, the "erroneous projection" in cases of paralysis of the right external rectus has been ascribed to abnormally great "in-going currents,"- to

4 Risien Russell refers in the first of the two of his papers we have mentioned to what we may call "the ocular part" of Sherrington's widely applying researches.

5 See Proceedings of the Royal Society of Medicine, June, 1908. 6 Helmholtz, Handbuch der Physiologischen Optik, Second German Edition, p. 762, wrote as translated in the following: "Not only does the position of the seeing eye but also the position of the closed eye infuence our determination of the direction in which the object looked at lies. If the opened eye remains stationary while the closed eye looks also has an apparent movement to the right or the left." currents arising from the over-contraction of, and to abnormally great periphero-central currents from, the left internal rectus. This explanation-" the in-going the ory" we have called it-was suggested by Professor E. M üller" and a little later by William James of Boston, U.S.A.

It occurred to one of us (J. H. J.) to test the "in-going theory" in a way to be now very briefly described; this is done only in order to state the first of three steps in an investigation. By an appropriately applied prism some of the effects of paralysis of an external rectus, we shall suppose the right, can be imitated. We say some of the effects because there is an exceedingly important difference between this "imitation paralysis" of the muscle and "veritable paralysis" of it from disease of the sixth cranial nerve. The man in the "prism experiment" is in a normal condition until the prism is placed before his right eye; with the prism over the right eye there is, when he tries to look to the right-when, so to say, he tries to overcome the prism-abnormally great turning in, technically, "secondary deviation," of the left, the closed, eye and there is "erroneous projection" of objects to the right. So far there will be no obvious difference in the two symptoms (" secondary deviation" and "erroneous projection") from those in a case of "veritable paralysis" of the right external rectus. But in the "prism paralysis" the right external rectus muscle is neither motorily nor sensorily cut off from the central nervous system, whilst in the veritable paralysis that muscle is motorily cut off from that system; and it is, in effect, sensorily cut off too since no contractions of it can occur to set up sensory currents from it to any centres. Indeed, there will be in the "prism paralysis" abnormally strong activity of the right external rectus, of which muscle there is the so-called "imitation paralysis," and thus there will be stronger in-going currents from the muscle. There will, moreover, be abnormally strong in-going currents from the over-contracting left internal rectus. 'Thus the prism experimentation on a normal man in regard to the "outgoing $v$. in-going theories" is not trustworthy (see remarks by L. P. close of Part IV.). These " prism experiments" it is suggested (J. H. J.) deserve a little consideration, as being the first step towards, and as being suggestive of, a better method of investigation. There is another way in which the prism may be used for the present research; but the statements about it are only given because they are a second step towards a better investigation.

We may ask what will happen to a patient in the "prism paralysis" of his right external rectus whilst he is looking to his right, for whom there is, in effect, no left internal rectus as when that muscle is paralysed as part of a left third nerve paralysis? Or the case of a man who has lost his left eye could be taken to test the "out-going $v$. in-going theories." In either of the two cases (loss of the left eye or paralysis of the muscles supplied by the left third nerve) let paralysis of the right external rectus be imitated, or rather (vide supra) partially imitated, by placing a prism over the intact right eye. Might we infer anything, from the presence or absence of "erroneous projection," when the patient tries to look to the right, whether or not abnormally great contraction of the left internal rectus is or is not necessary for the production of the "erroneous projection" which occurs in a case of "veritable paralysis" of the right external rectus? But we have again to note that in the two kinds of cases remarked on in this paragraph there will be strong in-going, periphero-central, currents from the strained action of the right external rectus during its "trying" to overcome the prism, to the over-action of this muscle the erroneous projection might be attributed. This suggestion is the second step in the inquiry. Now for the third step. ${ }^{9}$

One of us (L. P.) suggested that the proper case for the present research would be that of a patient in whom not only are the muscles supplied by the left third nerve paralysed, but in whom the right external rectus muscle is paralysed too. Such a case has lately been met with. The patient is in the National Hospital, under the care of our colleague, Dr. F. E. Batten, whom we have to thank for permission to publish particulars of the case. We have also to thank Dr. H. P. Gibb for an important part of the notes.

Zur Grundlegung der Psychophysik, 1878.

8 Principles of Psychology, vol. ii., p. 506 et sec.

9 What I call the third step is by far the most important one; it is

founded on Mr. Paton's suggestion. This part of the research (see
Part V.) was made by him. (J. H. J.) 
Mr. Paton has examined the ocular condition of the patient and gives an account of his examinations in Part $\mathrm{V}$.

(The remainder of this article (Parts II., III., IV., V., and VI.) is written by Mr. Paton.)

PART II.-An Account of some Experiments in Partially "Imitating" the Effects of Paralysis of an External Rectus in Normal Subjects by Means of a Prism.

In these experiments I (L. P.) have throughout used a $12^{\circ}$ prism and have assumed the refractive index as approximately 1.5. The distance of the eye from the object in each case has been about $18^{\prime \prime}$; with the prism of $12^{\circ}$ placed accurately in front of one eye the displacement of image produced at this distance should be theoretically slightly under 2 . ${ }^{30}$ The difficulty first met with was that as soon as the finger with which the man who was being experimented on was asked to point at the object, came within his field of vision, it also was subject to the same displacement as the object and was guided in (or out) towards the object. This difficulty was overcome by using an ordinary writing pad held under the man's chin. At the far end of the pad a cross was drawn on the paper close to the edge, and on either side inch spaces were marked out. The man experimented on was then asked to bring a pencil or a penholder along the under surface of the pad and to place its point exactly opposite the cross. In this way he was unable to see the morement of his hand and was not conscious of any error in his power of projecting until he saw the point of the penholder appearing at the far edge of the blotting pad and some distance to the right or left of the marked cross.

I tried this experiment on a series of normal individuals, most of them medical students at St. Mary's Hospital or clinical assistants at the Royal London Ophthalmic Hospital. In the majority of these men the projection with each eye separately without a prism was very accurate; the pen's point was placed exactly at the cross. In a few, however, there was a tendency to project a little to one or other side of the cross when one eye was covered and the men who had this deficiency in power of projection mostly showed a slight heterophoria (usually exophoria).

Testing the whole series of healthy men experimented on with $12^{\circ}$ prism I found that in every one there was a displacement of the image of from $1_{2}^{\prime \prime}$ to $2^{\prime \prime}$. In the case of the man who had slight false projection to start with (this was never more than half an inch) the displacement was always $1 \frac{11}{2}$ to $2^{\prime \prime}$ from the point of false projection.

To resume: the image in all these normal persons was erroneously projected in the direction in which the eye with the prism in front of it was looking, and on uncovering the other eye that eye was always found to be looking towards the point to which the image had been falsely projected, that is to say, there was apparent "secondary deviation" of that eye.

PART III.-Cases of Paralysis or Paresis of the Third Nerve Wuscles of One Eye in rhich the Prism Experiment was Tried.

CASE 1.-Patient 54 years of age (Moorfields). Paresis of muscles supplied by the left third nerve and right-sided facial weakness. Left Eye: Cataract. The left pupil was dilated and was inactive to light and during attempts at accommodation. The upward, downward and inward movements of this eye were almost absent. Outward movement was good. Right Eye: V. $=\frac{6}{18}$ c. +1 D. Sp. $=\frac{6}{6} .{ }^{11}$ With the right eye uncovered the patient's projection was accurate. He brought the pointer up exactly opposite the cross each time. On putting a $12^{\circ}$ prism, base inwards, in front of the right eye, he projected the cross when it was at $18^{\prime \prime}$ distance from his eye invariably $2^{\prime \prime}$ too much to the right. On trying him with the same prism base outwards he projected the mark $1_{\frac{1}{2}}^{\prime \prime \prime}$ to the left of its true position.

CASE 2.-Patient, 42 years of age (Moorfields). Paralysis of left internal rectus, slight paresis of right internal rectus and of the right superior rectus, occasional ptosis. In this case on testing the projection of the paralysed left eye, the amount of false projection was found to be about $7^{\prime \prime}$ to the right of the object aimed at. The left eye was then covered and a $12^{\circ}$ prism, base inwards, was placed in front of the

10 It was found in a large number of observations on normal people that this amount of displacement was very regular.

11 The right eye was slightly long-sighted but with the proper glass bis vision was normal. right eye. The cross was then projected about $2^{\prime \prime}$ to the right of its true position.

CASE 3.12-Complete third-nerve paralysis right eye. The right eye can move inwards past the middle line to the extent of less than $10^{\circ}$. It possesses almost full outward movement. Upward movement practically non-existent. Downward movement very limited and accompanied by marked rotation. The movements of the left eye are good in all directions. On asking the patient to aim with the pen at a cross drawn on the blotting pad 18" away from the right eye with the left eye covered, he always gets fairly good projection, the tendency being to project occasionally a little to the left but never more than $1^{\prime \prime}$. When the right eye (the paralysed eye) is covered and he is asked to bring the pointer up opposite the cross with the uncovered left eye, he brings it up at distances varying from half an inch to an inch and a half to the right of the cross. When a prism $11^{\circ}$, base inwards, is placed in front of the left eye, he then projects the cross sometimes absolutely correctly, sometimes about half an inch to the left. Most frequently his projection is correct. When the prism is placed base outwards the projection of the image varies between $2^{\prime \prime}$ and $3^{\prime \prime}$ to the right of the mark.

CAsE 4.- National Hospital for the Paralysed and Epileptic.) This case was shown to me as a case of paralysis of the right third nerve. On testing the supposed sound eye, the left eye, it was found that the patient projected objects about $~_{\prime \prime}^{\prime \prime}$ too much to the right and consequently putting a $12^{\circ}$ prism, base inwards, in front of the left eye he got accurate projection, pointing to the probable existence of paresis of left internal rectus as well as to right third nerve paralysis. This case, of course, differs from the others mentioned, but is worthy of note in that the change in the projection produced by the $12^{\circ}$ prism was the same as in the other cases.

CASE 5.-Patient aged 57 years. Complete paralysis of right third and fourth nerves. First saw double four years ago. Ptosis developed last September. Action of orbiculares palpebrarum good. Left eye weak as a child. Hypermetropic in buth eyee. Vision with correcting glasses good in each eye. On testing this patient's power of projection with her left eye it was found to be accurate. On placing a prism of $12^{\circ}$, base inwards, before her left eye she misplaced the cross $2^{\prime \prime}$ to the left of its true position.

CASE 6.-Right eye removed and contents of orbit eviscerated for endothelioma of the orbit. On testing patient's normal power of projection with her left eye it was found to be fairly accurate, the variation being under half an inch on either side of the mark. With a $12^{\circ}$ prism, base in, before her left eye, she misplaced the cross $2^{\prime \prime}$ to the left. With the prism outwards she misplaced the cross 2 " to the right.

I have examined many other such cases on the lines suggested by Dr. Jackson with similar results in them all. I have also measured in many of these cases the error of projection in the affected eye with the head held in various positions, and I have compared the angle of deviation in projection with the angle of secondary deviation of the unaffected eye. I have found that these practically never correspond, the secondary deviation of the unaffected covered eye being, as a rule, much greater than the angle of false projection.

\section{PART IV.-Remarks by L. P. on the Results of Experiments with Prisms.}

In these cases of paralysis or paresis of the muscles supplied by one third nerve, the other, the normal eye, being covered by the prism, base inwards, the patient when told to look at an object on the side of the eye which is covered with a prism must turn the eye out slightly in order to get the image of that object on to the macula ; therefore the projection of the object might be supposed to be due to the impulses sent up from the external eye muscles indicating the true position of the globe. The false projection might, in fact, be said to ise due in this case to afferent impulses as the projection takes place exactly in the direction in which the eye is turned by the action of the external muscles. I incline to think that these experiments, so far as I have been

12 The ocular paralysis in this case was of considerable standing and the history of the case renders it probable that the left eye had been affected by some ocular palsy as well as the right eye, though to a much less degree. 
able to try, only indicate that the false projection induced by a prism on the right eye, in cases of third nerve paralysis of the left eye, can be explained by the change in the position of the right eye, brought about in order to get the image focussed on the macula. This change in the position of the eye will be brought about by alterations in the relative contraction of the various muscles of that eye capable of developing afferent impulses. These experiments cannot therefore be regarded as an aid to the solution of the problem of "out-going versus ingoing currents." Stating this in another way, I may say as an axiom that a man possesses accurate power of projecting when he projects an object in the line of the axis of the pencil of incident rays entering his eye. If by some means external to his eye these rays are deflected before they reach his eye and after leaving the object, we should regard him as possessing normal power of projection only when he projects the object in the direction of the axis of the rays after deflection and as they reach the eye. That is to say, he ought to project" the objects a definite distance to the right or the left of its position, the distance varying with the prism employed, and if he does so his power of projection may be said to be true, since in this case the falsity is introduced by something external to himself. In the case of paralysis of an external rectus the falsity is introduced by a defect in the ocular mechanism, central or peripheral, of the man himself. In other words, I would not regard these prism experiments as proving anything in regard to false projection and its origin in cases of paralysis of eye muscles, except in so far as they render doubtful the part that the covered eye plays in determining the line of false projection. ${ }^{13}$

PART V.-Examination of a Case of Complete Paralysis of Left Third Nerve with Paresis of the Right Third and Paralysis of the Right Sixth Nerves. (General Notes by Dr. H. P. Gibh, House Physician, National Hospital for the Paralysed and Epileptio.)

Patient, aged 36 years. Case of polioencephalitis superior (Wernicke) under the care of Dr. Batten, ${ }^{14}$ was admitted for ocular paralysis of sudden onset affecting both eyes. Family history is unimportant and he himself has always had good health. He denies having had venereal disease, says he is moderate in the use of alcohol and shows no symptoms of lead poisoning. Two months before admission, while in his usual health, he felt his left eye to be closing. In half an hour the eye had closed completely. He worked all that day, and has done so regularly since and has had no trouble beyond this closing of the eye. No diplopia at the time and only on one occasion since-about a week after onset-when walking downstairs he looked downwards and saw two steps where there was only one and slipped. He has never noticed any other peculiarity about either eye. When the condition came on he had no discomfort; no headache, no sickness; felt in normal health, but since then he has had frequent headache coming on chiefly in the early morning and towards night. He has never vomited. No weakness in limbs at onset or since. No paræsthesiæ in limbs. No difficulty in speaking or swallowing. No symptoms suggesting tabes. No lightning pains: no bladder troubles: no unsteadiness in gait. The patient is a well-nourished, healthy looking man. His memory, attention and cerebration are all good. Heart normal. Pulse tension not varied; blood pressure $120 \mathrm{~mm}$. of mercury. No thickening of vessels obvious to palpation; no changes in retinal vessels pointing to arterial degeneration. Urine contains no albumin or sugar. With the exception of II., III., IV. and VI. the cranial nerves are normal. The motor system of neck, arms, trunk and lower extremities presents no abnormality. There are no sensory changes. Supinator, triceps, and biceps jerk are very active and equal on the two sides. The abdominal reflexes are present and equal. The kneejerks and ankle jerks are equal on the two sides. There is no ankle clonus. The plantar responses are flexor.

$$
13 \text { See previous quotation from Helmholtz. }
$$

14 The following note about this case is supplied by Dr. Batten. * This is a case of polioencephalitis superior hemorrhagica (a condition originally described by Wernicke) due to a vascuiar lesion usually oocurring in alcoholic subjects. The autopsies in such cases have shown numerous punctiform hæmorrhages confined to grey matter in the floor of the third and fourth ventricles and in the aqueduct of Sylvius. Such a lesion results in damage to the oculo-motor nuclei or to the Wilbrand and Saenger. Die Neurologie des Auges, vol. i., S. 264."
Report of Examinations of the Eyes by $L . P$.

The patient was admitted for ocular paralyses of sudden onset affecting both eyes, the left more than the right. The vision of the right eye without correcting glasses equalled $\frac{6}{12}$ Snellen (half normal), in the left eye $\frac{6}{18}$ Snellen (one-third normal). There was no limitation of the fields of vision to rough testing though both optic discs were pale, the left more than the right.

Ooular movements.-Right eye: The right eye shows no drooping of the upper lid, though there seems to be an occasional slight tendency for the lid to fall a little. This, however, is only momentary. The upward movement of the right eye is moderately good, the downward movement is only fair, inward movement is quite distinct, though reduced to about one-quarter of the normal, outward movement very limited. The right pupil reacts fairly well to light and on convergence, so that in the right eye there is paralysis of the sixth nerve with paresis of the third nerve. Left eye: The left eye has complete drooping of the upper lid (ptosis). In rest position the eye is widely turned outwards, showing only two to three millimetres of sclerotic at the outer canthus. There is no power of upward movement. On attempting to look down there is very marked rotation of the eye (action of the superior oblique in position of extreme outward deviation). On attempting to look inwards the eye does not pass the middle line. Ontward movement is good. The left pupil is immobile in a position of semi-dilatation. The left eye then shows complete paralysis of the third nerve with the fourth and sixth unaffected. There is no weakness of the orbicularis palpebrarum on either side.

In testing the patient's ability to project accurately a blotting pad, 18 inches long, was used in the manner already described. The drooping of the left upper eyelid prevented him using that eye at all while we were testing the projection of his right eye. I first asked him to aim steadily at the cross whilst his head was in the middle line and in such a position that there was no attempt to use either his external or internal rectus muscle, i.e., right eye in primary rest position. In this position he managed to point with fair accuracy to the cross. His head was now turned to the left to such an extent that by using all the power of abducting he possessed he could still fix the cross. Under these conditions he pointed four inches to the right of the cross, i.e., a false projection of four inches at a distance of 18 inches. On now turning his head to the right in the same way, so as to bring into play the full power of his paretic adductor muscles, the pointer was brought up to a spot about four inches to the left of the cross. In other words he in both cases projected too far in the direction of the paretic muscle he was trying to use. His left eye remained during these attempts of course in a position of deviation varying a little as his head was turned to the right or to the left, but in no case was its visual axis directed anywhere near the place where the pointer appeared. We now covered his right eye and held his left eye open and asked him again to aim at the cross. When his head was held in the middle line it was a great effort for him to get the left eye fixed on the cross at all, and he pointed between eight and ten inches to the right, i.e., an error in projection of nearly $30^{\circ}$. On allowing him to turn his head to the extreme right so that he could look at the object aimed at with practically no feeling of effort at all (position of extreme relaxation of paralysed muscle), he managed to point with fair accuracy. On now examining the position of the right eye it was found to be only slightly deviated in from the middle line. The result of the examination of this case seems to me to be definitely opposed to the hypothesis that the false projection in the case of an eye where one of the muscles is paralysed may be due to impulses coming up from the mnscles of the sound eye.

In this case afferent impulses from the muscles of the left, the covered, eye can have no influence on projection whilst the right eye is being used since the left eye is always in a position of left deviation. With the right eye in the primary position the projection was accurate, but as soon as either of the paretic muscles, the right external rectus or the right internal rectus, was called into action, the patient got false projection (in the direction of action of the respective muscles). This false projection was not due to false position of the eye since the image of the object looked at was still formed on the macula in the positions in which 
the head was held. The movement of the patient's hand was not coördinate with the amount of movement which had actually taken place in the eye, but with the amount that the patient had willed to take place. A certain impulse had started out from the cortical oculo-motor centres. It had been partially blocked on its way to the eye muscles but had produced its full coördinating effect on the motor centre for hand and arm movement. It may, however, be suggested that accompanying the blockage of impulses on their way down to the muscle there may be some disorder of the returning impulses from muscle to the brain cortex. But a moment's consideration will show that this, if it does occur, as is possible, would probably be in the nature of a further blockage and that the brain would in that case register a less contraction than had actually occurred, and the resulting false projection, instead of being in the direction of action of the paralysed muscle, would be in the reversed direction.

PART VI.-The Results of Forced Displacements of the Eye :

the Nature of the Erroneous Projection in Such Cases and the Nature of the Vertigo.

The patient whose case has been discussed in the preceding section had at no time any vertigo. Even with his head held in a forced position there was no staggering in his gait nor feeling of giddiness. At Dr. Jackson's suggestion I have tried on myself and on other normal individuals the effect of forced displacements of the eye in producing erroneous projection and a feeling of vertigo. If a finger is pressed into the outer corner of the right eye, a crossed diplopia can be produced ${ }^{15}$ and with a little care the downward displacement can be eliminated and one can-obtain a simple horizontal displacement of objects, as seen by the right eye, to the left. The eye, in these circumstances, has been rotated outwards and a paralysis of the right internal rectus is simulated. The range of false projection that can be produced in this way varied from two to five inches. It is much more difficult to produce an internal rotation by pressure on the inner part of the eye. Usually a large phosphene appears and vision is interfered with before any marked displacement of objects takes place, but a slight amount of rotation can be produced with seeming displacement of objects (to the right in the case of the right eye, i.e., simulation of paresis of right external rectus). When I produce the first of these displacements on my own right eye, it causes no sensation of vertigo while I have both eyes open. As soon as I cover my left eye a feeling of giddiness comes on ${ }^{16}$ and on walking the gait is of a staggering nature, with distinct tendency to fall to the right. The vertigo may last for some time after stopping the experiment. I am unable to produce for a sufficiently long time the effect of pressure on the inner side of the right eye, so that I cannot say definitely whether the tendency in that displacement is to fall to the left. Pressure on the outer side of the left eye produces a staggering to the left side. Only one of the normal individuals whom I have asked to try this experiment had any feeling of giddiness while the untouched eye was uncovered. In the others the vertigo dereloped only on covering the eye which was not the subject of experiment. And in every one the tendency was to fall away from the side towards which the objects were displaced.

\section{SOME POINTS IN THE TREATMENT OF NERVOUS DISEASES. ${ }^{1}$}

BY JAMES TAYLOR, M.D. EDIN., F.R.C.P. LOND., PHYSICIAN TO THE TATIONAT HOSPITAL FOR THE P'ARALYSED AND EPILEPTIC, QUEEA-SQUARE, AND TO MOORFIELDS KYE HOSPITAI; CONSULTIYG PHYSICIAN TO THE QUEEY'S HOSPITAI FOR OHILDREN, LONDON.

IN order that we may, in so-called nervous disease, adopt the measures best calculated to promote amelioration or cure it is essential to recognise the true nature of such disease. In many diseases which are called nervous the disease is not primarily in the nervous system itself. The functions of that system may be interfered with, because the nutrition of

15 Pressure at the outer canthus can also produce a homonymous

diplopia. Personally I find it easier to produce crossed diplopia.

${ }_{18} \mathrm{On}$ this point see von Graefe, "Des Paralysies des Muscles de l'Oeil," p. 11, French edition, 1870.

1 A paper read before the Streatham Branch of the British Medical Association on Jan. 28th, 1909. nervous elements is impaired in consequence of the derangement of some other tissue or organ. Thus, in the condition which we know as hemiplegia, in which one half of the body is paralysed, this paralysis is the result not of any inherent primary defect in the nervous system itself but of an interference with the nutrition of a part of the nervous system due to an interruption of its vascular supply. In other words, hemiplegia really depends upon a diseased or defective condition of the vascular system, leading to impaired function of the nervous system. This impairment may be of varying degree, and according to the degree and extent of impairment so is the character-severe or slight, restricted or widespread - of the paralysis.

\section{The Causes and Treatment of Hemiplegia.}

This leads us to consider the different causes of ordinary hemiplegia and the means to be adopted in its treatment. Hemiplegia may be the result of (1) rupture of a bloodvessel, resulting in a cutting off of the blood supply of a part of the nervous systen and consequent impairment of the function of that part ; there may also be a tearing up of nerve fibres and pressure on neighbouring parts, the result of the blood slot; and there may also be some degree of inflammatory change in the vicinity of the blood clot. But these changes, as will be seen at once, are really the result of vascular disease, and it is to the condition of the vascular system that one's thoughts must be directed if treatment is to be efficacious. When hemiplegia is the result of a ruptured vessel examination will usually lead to the recognition of a high blood pressure, with perhaps considerable cardiac hypertrophy, and it may be found that it is associated with albuminuria, the result of cirrhosis of the kidney. In such a condition consciousness is usually abolished, the breathing is stertorous, and the temperature raised. The unconsciousness may be profound-a condition of actual coma-and the respiration may be of the Cheyne-Stokes variety. In other cases the constitutional symptoms may be slight, but in any case they may last for weeks. But hemiplegia may be the result (2) of thrombosis in a blood-vessel, leading to abolition of the function of the part of the brain supplied by this vessel. Here, again, the symptoms of nervous disturbance are secondary to a diseased condition of the vessel, with possibly a morbid state of the blood-a state in which it is liable to clot, while a roughened and diseased blood-vessel furnishes it, so to speak, with a good excuse for clotting. In such a case we have the function of a part of the brain involved dealt with in a much more gentle way and the constitutional effects are in consequence much less sthenic. In an aged person the attack of paralysis from thrombosis usually occurs during rest-very frequently in the night, and although the hemiplegic condition is unmistakeable the constitutional condition may be one in which little or no disturbance is obvious-there may be no rise of temperature, no evidence of profound alteration, the pulse may remain slow and quiet and regular, and consciousness may, and usually does, remain quite unimpaired. But such a condition may arise in a young person in whom the vascular condition cannot be supposed to be the result of senile changes and in whom there is no evidence of visceral disease. The thickening of the vessel wall in such a case is the result of syphilitic endarteritis, and the symptoms at the onset in such a patient are similar in every way to those accompanying the onset of hemiplegia in a patient with senile atheroma. There may even be no headache, for as a rule the syphilitic cases with headache are those in which there is a presumption that syphilitic meningitis is present. Yet it must not be forgotten that in such cases vascular disease may also be present so that the presence of headache in any case of hemiplegia is not incompatible with the likelihood of this being due to blocking or thrombosis in an artery the seat of syphilitic endarteritis. It may be stated generally that hemiplegia occurring in a person under 40 years of age, in whom there is no evidence of cardiac hypertrophy or cardiac disease or kidney change, is to be presumed, for purposes of treatment, to be the result of syphilis.

But yet another variety of hemiplegia (3) should be mentioned-that, namely, in which the onset is quite sudden and may be attended or not with loss of consciousness. When consciousness is lost in the class under consideration-the class, namely, in which heart disease or aneurysm is recognised to be present and in which the lesion is 